\title{
Personal Privacy Evaluation of Smart Devices Applications Serving Hajj and Umrah Rituals
}

DOI : 10.36909/jer.13199

Mohd Khaled Shambour*, Adnan Gutub**

* Custodian of the Two Holy Mosques Institute of the Hajj \& Umrah Research, Umm Al-Qura University, Makkah, Saudi Arabia.

** Computer Engineering Department, Umm Al-Qura University, Makkah, Saudi Arabia

**Email: aagutub@uqu.edu.sa; Corresponding Author.

\begin{abstract}
Mobile Applications (apps) are one of the most important tools that provide many services in different and varied fields of human life such as social, health, commercial, political, and other services. These apps make information easily available to everyone, fast to get, and cheaper than traditional methods. The Hajj pilgrims and Umrah performances (Al-Rahman Holy guests) have a share of the electronic services provided by many governmental and private sectors inside the Kingdom of Saudi Arabia. The offered services ensure that these religious guests have the ability to gain useful knowledge before and during the period they are stayed in the land of the Two Holy Mosques. In this paper, we collected all possible apps related to Hajj and Umrah, from the Google Store, during the season of Hajj $1440 \mathrm{AH}$ (2019 AD), which amounted to 471 apps through searching on relevant applications to Hajj and Umrah services. We studied the applications public info trying to gain personal privacy characteristics from user rating, number of evaluators, recent updates, volume of applications, languages, number of downloads, and specific services provided. The results showed that the largest percentage of the studied apps are the facilitations of the Hajj ritual with $18 \%$, followed by $15.1 \%$ for Umrah ritual and $10.2 \%$ for prayer supplications. The results also indicated attractive 33 common languages used, showing English with most popularity of $27.4 \%$, followed by Arabic and Urdu of $24.3 \%$ and $14.3 \%$. In addition, the study specified the most desirable services favoured by the religious guests expressing interesting valuable remarks.
\end{abstract}

Key words: Hajj services; Islamic pilgrimage; services; mobile applications; google play; analytical study. 


\section{INTRODUCTION}

Every year Millions of Muslims come to Saudi Arabia to perform Hajj and Umrah rituals (Shambour \& Khan, 2019). These religious visitors are known as Al-Rahman guests pretending their main purpose of visiting is the holy lands and holy house of Allah. Many government and private sectors provide various services to Al-Rahman guests to facilitate their worships performance (Kaysi et al., 2013). Among the most prominent services provided to the guests of the Two Holy Mosques are electronic services (e-services), which facilitate the flow of various procedures and requests and save a lot of time and effort for its users who go to the Two Holy Mosques (Khan \& Shambour, 2018, Aly \& Gutub, 2018). The mobile apps for Hajj pilgrims and Umrah performers are considered one of the important e-services as they provide information and guidance in various fields that the guests need before they arrive and during their visit until they return back to their countries. In fact, mobile apps can be essentially used for emergencies situations, such as medical health requirements (Samkari,\& Gutub, 2019) and identifying lost and found people (Gutub \& Aly, 2018), as well as guiding the elderly and needy persons to their proper paths' directions (Kim et al., 2015) and giving urgent priority guidelines within the crowds (Curtis et al., 2013). The mobile apps are to be used for convenient scheduling of transportations plans (Kaysi et al., 2012) and providing full assistance against possible security and cyber threats attacks (Alsaidi et al., 2019). This current technology adoption is part of the national strategy stressed by Saudi Arabia Kingdom vision 2030 to involve smart systems, artificial intelligence, and internet of things, as main contributor serving all important Hajj and Umrah sectors (Farooqi et al., 2019). Therefore, the Saudi government is working to involve information and communication technology (ICT) in all its facilities for information gathering (Aly et al., 2014), data dissemination (Aly et al., 2013), and deeply use it for smart decision-making within Hajj and Umrah services (Alharthi \& Gutub, 2017). The government also pushed preparing the next generation (local students) to be geared fully via information technology (Almutairi et al., 2020). It further involved specific security stego-facilities to make ease of ICT accommodating all different backgrounds and 
educational levels (Almutairi et al., 2019).

In this research, the key criteria were defined to measure and evaluate the apps of Hajj and Umrah pilgrims (Al-Rahman's guests) with the aim of gaining personal privacy characteristics as well as future proper development as IoT progress within Hajj and Umrah recently evaluated by Shambour \& Gutub (2021). The work is to ensure the achievement of the apps desired results and goals, i.e. in providing the best trusted services for the guests of Al-Rahman. This apps study in relation to Hajj \& Umrah activities can be explored differently than normal real-life mobile apps detecting four special limitation aspects, namely variation of mega crowded users, stressed service providers, restricted physical geographic locations, technical mobile computation irregularity. The users people visiting the holy cities of Makkah and Madinah increases dramatically during the Hajj and Umrah seasons (planned reaching 30 million, following vision 2030 of Saudi Arabia), as does their use of information technology and communication networks beside all IoT current applications. Hence, the quality of services provided over various e-networks is adversely not readily affected. Also, note that Hajj and Umrah apps development are still in their beginning stage of very imperfect implementations, not based on research, that needs uncommon measurement and evaluation of the computing mobile apps technicality and practicality. This study specialty is ringing the bell for considering the Hajj and Umrah privacy concerns found exceptional serving guests whom are coming to the holy sites once in life, after long waiting years, visiting on one occasion and mostly not going to come again. Therefore, their acceptable experience is very vital and important demanding to be focused on, with unique dedication of apps platforms, built to be applied and tremendously tested within Makkah ritual land that is not very smooth respecting all aspects. For example, the visiting geographically holy sites is full of high mountains, connected all around via long tunnels, making the common communication technology and mobile platforms in real challenging situation needing urgent dedicated research. Furthermore, the specialization of this exploration is considering the variations of multi-cultural and multi-education poor variation of users whom suffer restricted resources on mega densely populated physical situations. The work found that these Hajj and Umrah apps need to run very special consideration of 
the Islamic rituals time limits suffering mega crowded surprises within very low (to sometimes lost) network connections, i.e. to be used by pilgrims whom mostly found different in their life-styles of rare unusual Islamic practices, may be coming as unorganized users. Normally, users are running the apps aiming to be served the best and not losing their personal desires and privacy characteristics as well as helping future apps developments to progress correctly and trustfully. The main objective of this work can be expressed as to ensure the achievement of the apps desired results and goals in providing the best trusted services for the guests of Al-Rahman. The research contribution scope is focused to highlight the personal information and services of mobile apps dedicated to the religious visitors, reveal of the most private characteristics of the common electronic services, and define applicable key criteria used to evaluate mobile applications. This study involved most needed Hajj and Umrah common features focusing on confidentiality and covering apps different languages, number of users, and user rating affected the social intellectual understanding as well as the groups personality and their collective influences. Therefore, for the open source convenience, the paper is currently directed to evaluate all possibly available apps published in "Google play "store at the time of research, which can be further used as privacy practical guide for any interested apps development (serving Hajj and Umrah) facilitations differently than general security technologies dedications platforms such as counting-based secret sharing (Gutub et al., 2019), or medical crypto security (BinHureib, \& Gutub, 2020) as well as image privacy (Hassan \& Gutub, 2021), and language dedication confidentiality (Gutub \& Fattani, 2007).

This paper is organized as follows. Section two briefly reviews the previous studies. Section three provides the research methodology adopted in this work. The results and discussion were presented in the fourth section. Lastly, the paper is remarked with the conclusion and recommendations, as the fifth and final section.

\section{LITERATURE REVIEW}

Stoyanov et al. (2015) developed a measurement tool called mobile app rating scale (MARS) to evaluate the quality of applications as well as privacy of persons using them. The MARS score is 
based on a five-point Likert scale consisting of 23 criteria covers four major personal rating categories: engagement, functionality, aesthetics, and information. Fraynt et al. (2018) also evaluated a set of apps designed to help retired people from military service to transition to civilian life, such as helping to find suitable jobs. The researchers used a group of six experts to evaluate 16 apps using the MARS evaluation tool. It was found that only two apps were downloaded more than 10,000 times from Google Play, and the majority were downloaded between 100 and 1000 times. The results also showed that only one application was rated above average, while half was rated below average. The researchers recommend making more high-quality apps and focusing on aspects of education and healthcare. Baskoro \& Widyanti (2018) conducted a study to evaluate the usability of Indonesian application for lending small companies in terms of effectiveness, efficiency and satisfaction. Data were obtained from a total of 60 participants who were asked to perform a series of tasks on the app. Chavez et al. (2017) assessed the quality of diabetes management apps for complement clinical care. The researchers used the MARS scale to assess the quality of 89 free and most popular apps for managing type 2 diabetes. In another study, Serra et al. (2015) evaluated four e-government apps in Brazil using the Web Content Accessibility Guidelines (WCAG) 2.0. Researchers analysed 61 criteria in WCAG 2.0. The results of the evaluations showed that many of the primary access problems, widely known by researchers in the field of human-computer interaction (HCI), were found largely in the evaluated applications. This highlights the importance of further research in evaluating smart device apps in order to provide more comprehensive access to basic apps that all citizens use, such as egovernment services. Khan and Shambour (2018) also conducted an analytical study of apps that provide variety of services for pilgrims and Umrah performers, in which 246 apps were studied from the Google Store and analysed according to four main criteria: services provided, supported languages, installation rates, frequency of services and application names.

Gafni (2009) defined a set of usability measurement for mobile devices including display load, clarity of operation capabilities, playlist completeness of operation menu, easy use of input and output, and self-adaptability of display. The author also linked the defined measures to three types of problems 
related to mobile wireless including network, device, and mobility. Finally, Nouri et al. (2018) conducted a survey for researches published between 2008-2016 related to health apps on mobile devices. The authors classified seven main criteria including design, information/content, usability, functionality, ethical issues, security and privacy, and the perceived value of the user.

It is evident from previous studies the importance of evaluating mobile applications, which aims mainly to improve and develop the services provided. As evidenced by the review of previous studies, the lack of specialized studies in evaluating apps concerned with serving privacy information of pilgrims and Umrah performers, which requires us to work and exert effort in introducing the multiple services provided by these apps and highlighting the most important personal characteristics associated with them.

\section{RESEARCH METHODOLOGY}

The methodology in this research is summarized in Figure (1), where the first stage begins with reviewing the literature searching for the appropriate keywords; In the second stage, an extensive analysis for Hajj and Umrah apps in the Google Store were conducted, which include the appropriate keywords, i.e. in the name or description of the application; In the third stage, ten apps related to government agencies in Kingdom of Saudi Arabia were privacy evaluated. After that, results and discussion were presented in the fourth stage, and the final stage offered the user personality remarks and future works.

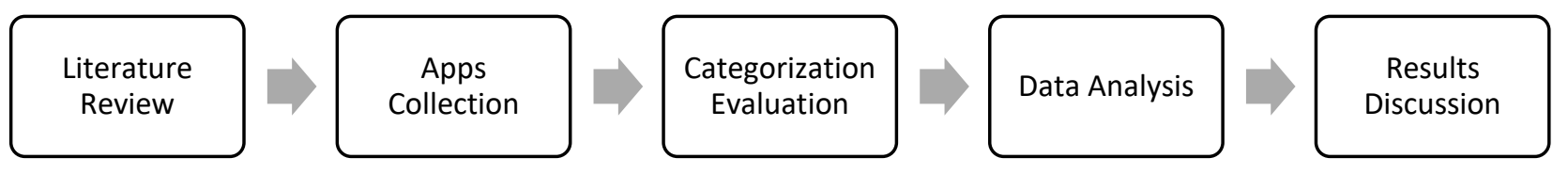

Figure 1 Research Methodology

\section{RELATED HAJJ AND UMRAH MOBILE APPLICATIONS}

This study includes 471 mobile apps collected from Google Play during Hajj season (Aug-2019) by searching of four common keywords, two Arabic and two English, namely (حم)(حم), and (Hajj), (Umrah), respectively. Our study based its research on the personal user privacy properties collected from each application commonly found consisting of nine elements, as shown in Table 1. 
Table 1 Features of Hajj and Umrah applications

\begin{tabular}{|c|c|c|c|c|c|c|c|c|}
\hline Attribute1 & Attribute2 & Attribute3 & Attribute4 & Attribute5 & Attribute6 & Attribute7 & Attribute8 & Attribute9 \\
\hline Name & Publisher & Services & $\begin{array}{c}\text { Download } \\
\text { Times }\end{array}$ & Language & $\begin{array}{c}\text { Number } \\
\text { of users }\end{array}$ & $\begin{array}{c}\text { User } \\
\text { Rating }\end{array}$ & $\begin{array}{c}\text { Latest } \\
\text { update }\end{array}$ & $\begin{array}{c}\text { Size } \\
\text { (MB) }\end{array}$ \\
\hline
\end{tabular}

Consider Table 1 indications, the apps containing names possibly reveled is the most common privacy info unfavored to be known. The publisher, services, download times, latest update, and size indications give ideas of the user influenced business model used as well as how trustful is the app from users' point of view adoption. In fact, some apps have been found from fake producers asking for charges without giving much of service. Others gave imprecise information making main causing of action by users affecting the crowd movements and activities, i.e. apps causing personal user clear confusions. The language, number of users, and user rating affected the private social intellectual understanding as well as the groups personality and their collective influences.

A total of 61 different services were observed from the collected apps including "Hajj Rituals", "Umrah Rituals", "Supplication", "Maps", "Images", "Videos", "Places of Visit", "Hajj News", and others. After that, statistical analyses were performed using basic statistical tools on the observed features of mobile apps as described in the following subsections.

\section{Accessible Apps Services}

Table 2 shows all the services that were observed from all apps, arranged in descending order from the most frequent service in the apps to the least frequent. The aim is to study the personal privacy information revealed from analysis of apps public data.

Table 2 Mobile application services

\begin{tabular}{|c|c|c|c|c|c|c|c|c|}
\hline 完 & $\begin{array}{l}\text { Service } \\
\text { Name }\end{array}$ & $\begin{array}{c}\text { Apps } \\
(\%)\end{array}$ & $\frac{\dot{\vec{\theta}}}{\frac{2}{4}}$ & $\begin{array}{l}\text { Service } \\
\text { Name }\end{array}$ & $\begin{array}{c}\text { Apps } \\
(\%)\end{array}$ & $\frac{\dot{0}}{2}$ & $\begin{array}{l}\text { Service } \\
\text { Name }\end{array}$ & $\begin{array}{c}\text { Apps } \\
(\%)\end{array}$ \\
\hline S1 & Hajj Ritual & $18.0 \%$ & $\mathbf{5 2 2}$ & Hajj in Quran & $1.1 \%$ & S43 & Hajj or Islamic History & $0.30 \%$ \\
\hline $\mathbf{S 2}$ & Umrah Ritual & $15.1 \%$ & $\mathbf{5 2 3}$ & Hajj in Hadith & $1.1 \%$ & S44 & Kids learning & $0.30 \%$ \\
\hline S3 & Supplications & $10.2 \%$ & 524 & Audio supplications & $1.1 \%$ & S45 & $\begin{array}{l}\text { Virtual and augmented } \\
\text { reality }\end{array}$ & $0.30 \%$ \\
\hline S4 & $\begin{array}{l}\text { Photos/diagrams/wallpa } \\
\text { pers } \\
\end{array}$ & $6.0 \%$ & $\$ 25$ & Hajj/Umrah handbook & $1.1 \%$ & S46 & $\begin{array}{c}\text { purposes and } \\
\text { provisions of Hajj }\end{array}$ & $0.30 \%$ \\
\hline S5 & $\begin{array}{l}\text { Video tutorial/ TV } \\
\text { episode }\end{array}$ & $3.7 \%$ & 526 & Tawaf counter & $1.0 \%$ & S47 & $\begin{array}{l}\text { Translation and text to } \\
\text { speech }\end{array}$ & $0.24 \%$ \\
\hline S6 & Maps & $3.6 \%$ & $\mathbf{5 2 7}$ & Talbia \& Tkberat & $0.97 \%$ & S48 & Islamic chants & $0.24 \%$ \\
\hline S7 & $\begin{array}{c}\text { Prayer schedule \& } \\
\text { timing }\end{array}$ & $3.2 \%$ & 528 & $\begin{array}{c}\text { Hajj tweets, social } \\
\text { media }\end{array}$ & $0.79 \%$ & S49 & light schedule & $0.24 \%$ \\
\hline
\end{tabular}


Journal of Engg. Research Online First Article

\begin{tabular}{|c|c|c|c|c|c|c|c|c|}
\hline S8 & $\begin{array}{c}\text { Hajj and Umrah agency } \\
\text { services }\end{array}$ & $2.7 \%$ & \$29 & $\begin{array}{l}\text { Hajj/Umrah program } \\
\text { and scheduling }\end{array}$ & $0.79 \%$ & S50 & $\begin{array}{c}\text { Advices from Umrah } \\
\text { performance }\end{array}$ & $0.18 \%$ \\
\hline S9 & Visit Al-Madina & $2.1 \%$ & $\mathbf{5 3 0}$ & Audio tutorial & $0.73 \%$ & S51 & Crowd status & $0.12 \%$ \\
\hline S10 & Q\&A/ fatwa & $1.9 \%$ & S31 & Regulatory services & $0.73 \%$ & $\mathbf{5 5 2}$ & Messenger \& SMS & $0.12 \%$ \\
\hline S11 & Religious or regular tips & $1.8 \%$ & $\mathbf{S 3 2}$ & Emergency services & $0.66 \%$ & $\mathbf{5 5 3}$ & Photo editor/ frames & $0.12 \%$ \\
\hline S12 & Do and do not & $1.5 \%$ & 533 & Hajj news & $0.54 \%$ & S54 & Booking a taxi & $0.12 \%$ \\
\hline S13 & Travel tips and checklist & $1.5 \%$ & S34 & Tasbeeh counter & $0.54 \%$ & $\$ 55$ & Traffic conditions & $0.12 \%$ \\
\hline S14 & $\begin{array}{c}\text { GIS/Bluetooth -based } \\
\text { guidance }\end{array}$ & $1.5 \%$ & $\$ 35$ & Greeting cards & $0.54 \%$ & S56 & Badal Hajj and Umrah & $0.12 \%$ \\
\hline $\mathbf{S 1 5}$ & Places to visit/ services & $1.5 \%$ & S36 & $\begin{array}{c}\text { Communicate with the } \\
\text { campaign }\end{array}$ & $0.48 \%$ & S57 & Lost \& found services & $0.12 \%$ \\
\hline S16 & $\begin{array}{l}\text { Information on Hajj } \\
\text { (phone numbers) }\end{array}$ & $1.4 \%$ & 537 & Complaint services & $0.42 \%$ & S58 & Hajj volunteers & $0.06 \%$ \\
\hline S17 & Compass & $1.3 \%$ & $\$ 38$ & Currency conversion & $0.42 \%$ & S59 & Funeral Provisions & $0.06 \%$ \\
\hline S18 & $\begin{array}{l}\text { Temperature and } \\
\text { weather }\end{array}$ & $1.3 \%$ & $\$ 39$ & $\begin{array}{l}\text { Accommodation } \\
\text { locator }\end{array}$ & $0.42 \%$ & 560 & Statistics & $0.06 \%$ \\
\hline S19 & $\begin{array}{c}\text { Health services \& } \\
\text { information }\end{array}$ & $1.3 \%$ & $\$ 40$ & Track hajj progress & $0.42 \%$ & S61 & Dictionary & $0.06 \%$ \\
\hline $\mathbf{S 2 0}$ & Live video & $1.3 \%$ & S41 & $3 \mathrm{D}$ & $0.30 \%$ & & & \\
\hline $\mathbf{S 2 1}$ & Complete Quran & $1.2 \%$ & S42 & Hajj tour & $0.30 \%$ & & & \\
\hline
\end{tabular}

Interestingly, it was found that the Hajj rituals service was presented in $18 \%$ of the total collected applications, followed by the Umrah rituals and supplications services by $15.1 \%$ and $10.2 \%$ respectively. The results also showed that the private services that are less available in apps are the services related to volunteering in Hajj, funeral provisions, statistics, and a linguistic dictionary which have a percentage of $0.06 \%$.

\section{Apps Download Times}

The personal downloaded times of apps on smart devices is one of the main private indicators of the users' desire to use the apps. Figure 2 displays the number of apps categorized by the specific number of download times. The results show that the individual highest rate of downloading apps was between 1,000 and 5,000 times, with a rate of $25.7 \%$. The trusted public results also indicated that the only application with the most downloaded belongs to the "Watch Live Makkah \& Madinah 24 Hours HD Quality" application, which is an application that supports live video services for the Two Holy Mosques in Makkah and Madinah, as it has been downloaded more than a million times. On the other hand, the "Watch Makkah \& Madinah Live 24/7 - Kaaba TV PRO" application, which supports the same direct transmission service for the Two Holy Mosques, had the lowest particular download rate, reaching $0.2 \%$, due to the fact that the specific application is not available for free use. 


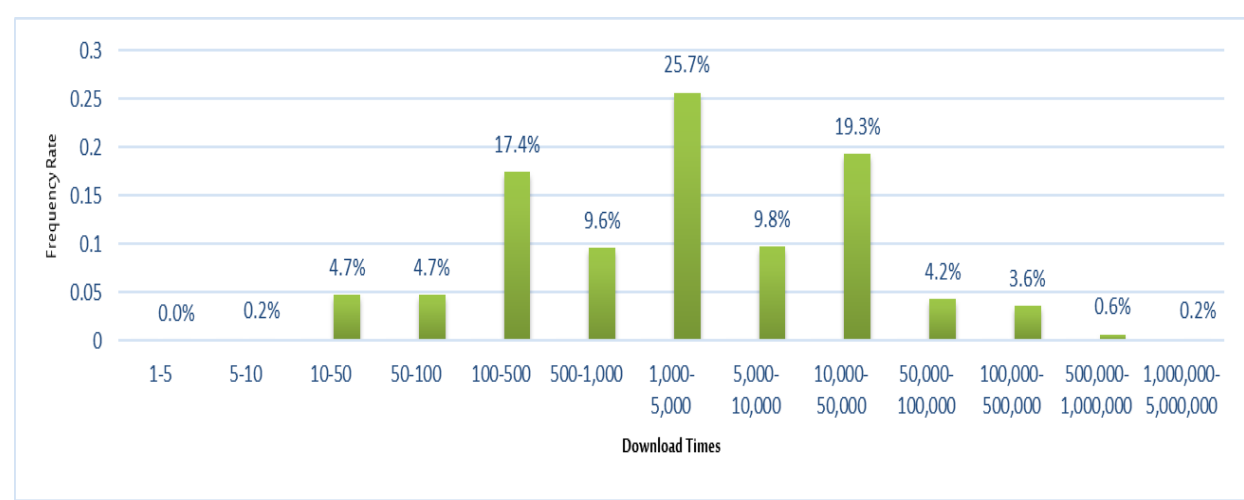

Figure 2 Download times of Apps

\section{Offered Apps Languages}

The study revealed personal privacy number of languages commonly used in the within the Holy sites, which reached 33 languages covering most of the languages during that period. Figure 3 shows the percentage of personal languages used in applications. It turns out unexpectedly that English language is considered still the most used language in apps with a percentage of $27.4 \%$, followed by Arabic and Urdu, at $24.3 \%$ and $14.3 \%$, i.e. as languages not common in the area.

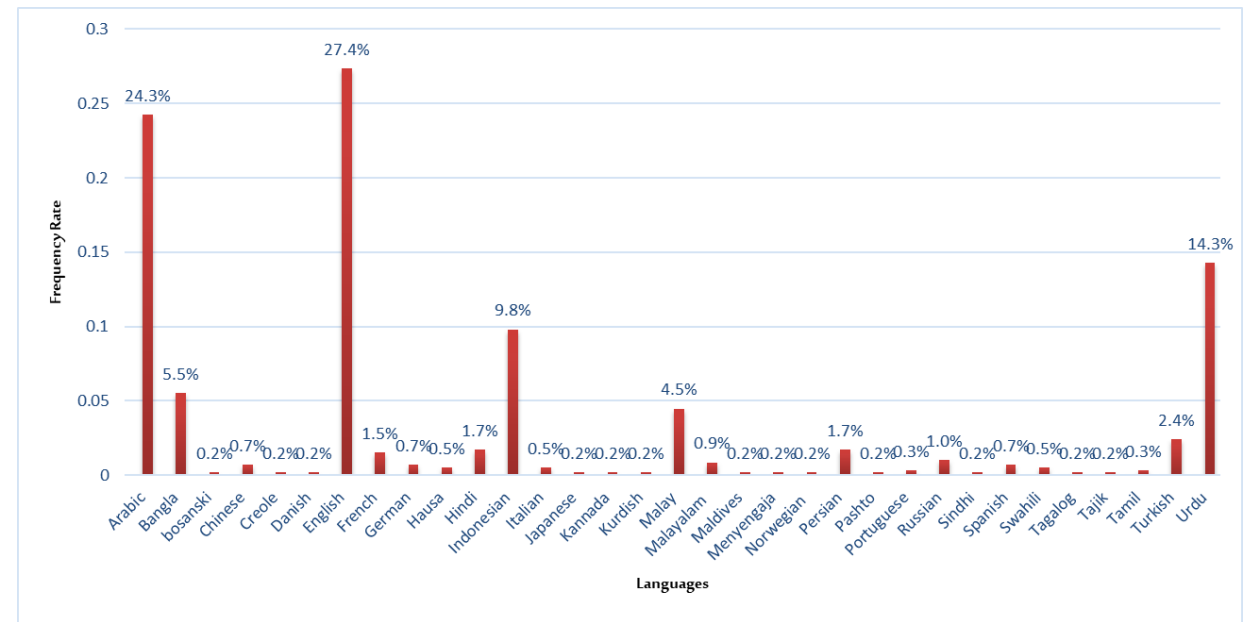

Figure 3 Private languages used in applications

The results of the analysis also showed that people suffered or complained that most apps support only one language, at a rate of $89.8 \%$, where personal apps preferred as supporting more than three language was $1.7 \%$ as shown in Figure 4. 


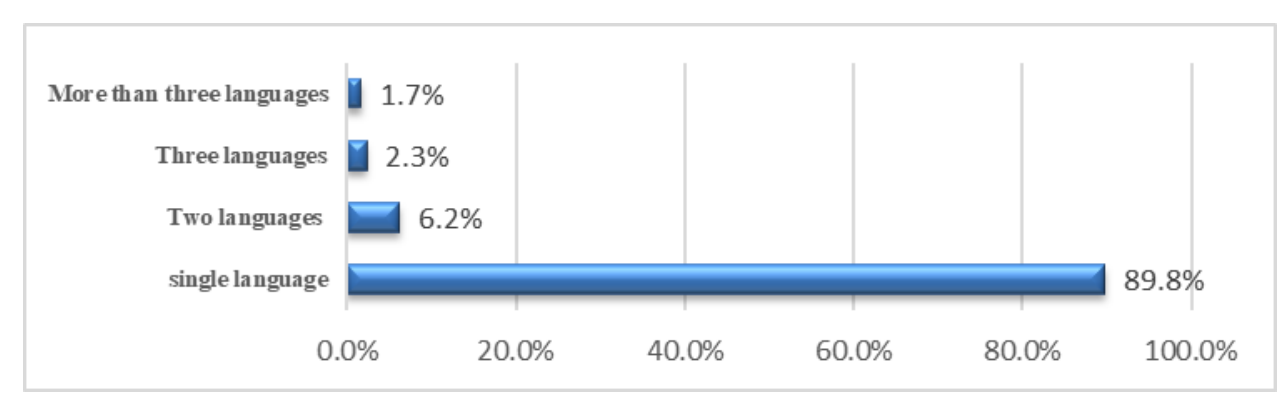

Figure 4 Categories for the personal number of languages supported by applications

\section{Recurring names and services of Apps}

The study and investigations showed that there is duplication in the names and services of the intended apps causing user clear confusions affecting his privacy. Figure 5 shows the names of duplicated apps that belong to more than one publisher making the personal info distributed undetectably. On the other hand, the results revealed presence of some apps claiming to provide similar personal services that are repeated and more ambiguously belonging to the same publisher. For example, Figure 6 briefs the percentage of apps with languages sharing similar services. The research show that Arabic and English languages are the most frequent used in the repeated apps. However, these types of similar apps need to reconsider privacy information that could be combined with each other to be presented as a single multilingual version.

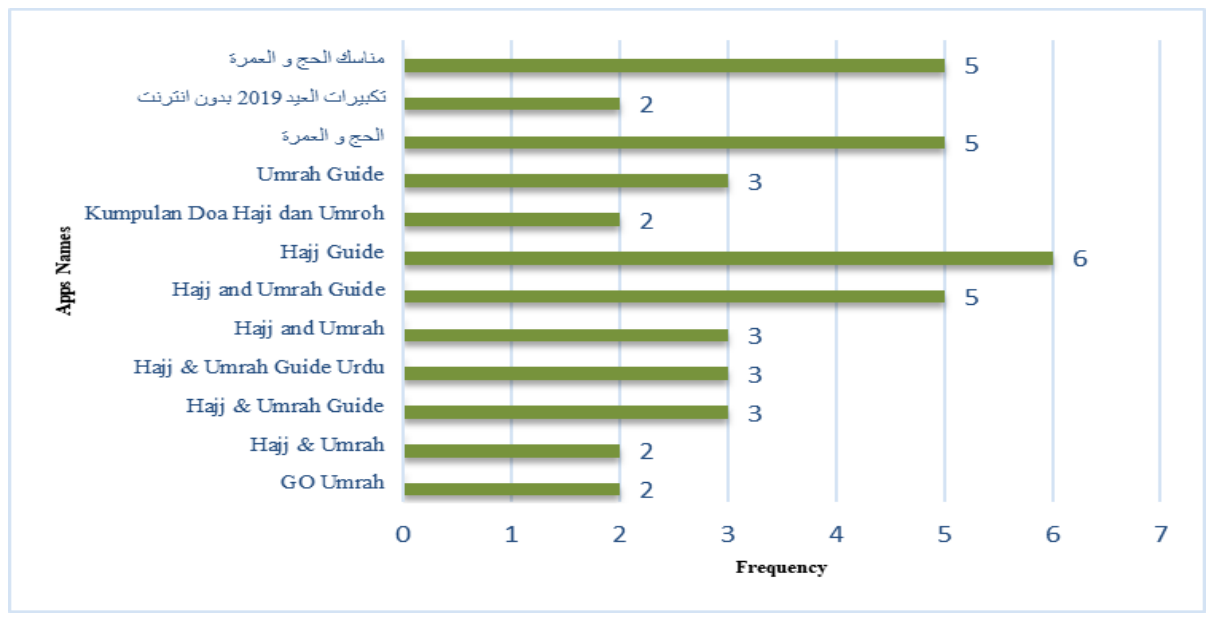

Figure 5 Duplication of App's Names and services 


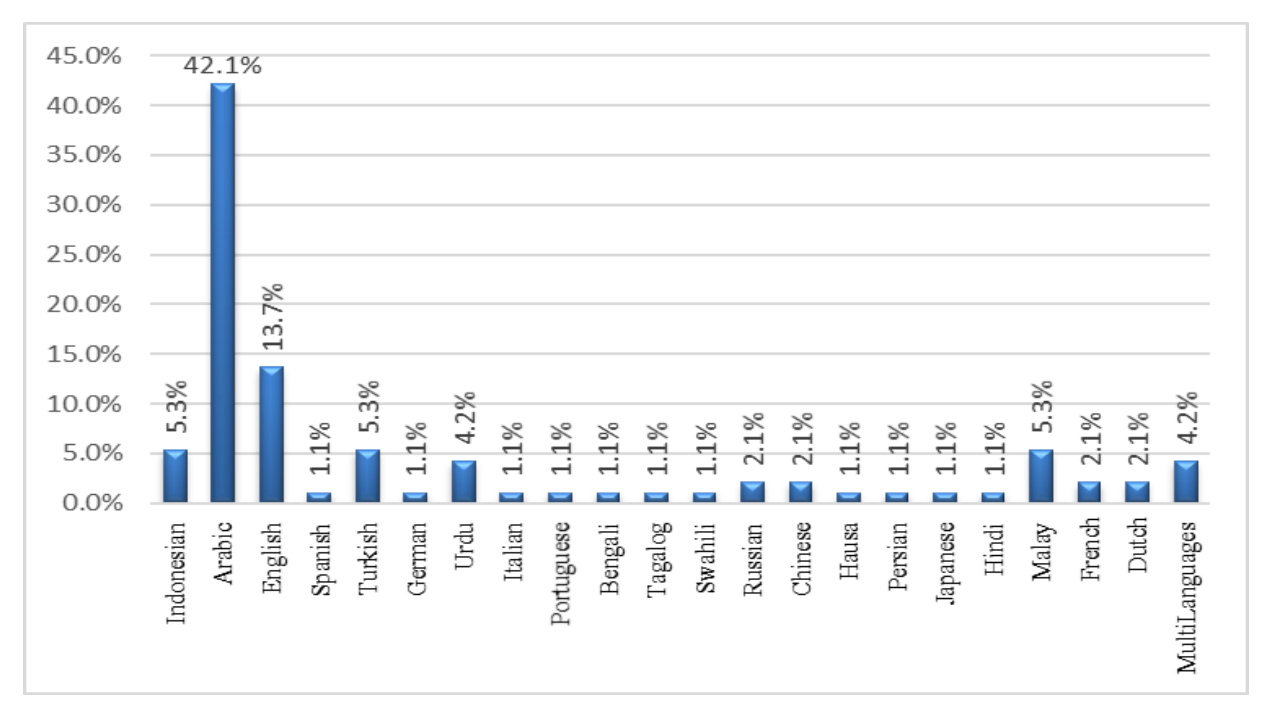

Figure 6 Apps languages that share similar services

\section{Rating of App Users on Google Play}

Figure 7 shows the results of studied apps combined with privacy evaluation scores divided into ten categories. It is noticed from the privacy figure that the apps that have not been evaluated are equivalent to nearly a third of the total number, with a rate of $32.7 \%$. The percentage of apps that were evaluated between [once - 100 times] amounted to $47 \%$ of the total number of evaluated applications, and this personally indicates the lack of users' desire to evaluate the apps they used, as they commonly perform the service once in life. On the other hand, the apps that were evaluated had excellent ratings, with ratings ranging from 4.5 to 4.7 out of 5 . It is worth noting that the application "Watch Live Makkah \& Madinah 24 Hours HD Quality" is the most highly rated program among personal usages, rated by 44,132 users. This high private evaluation rate is of more than $35 \%$ of the total number of times the assessment of all apps with attractive evaluation rate of 4.8 out of 5 .

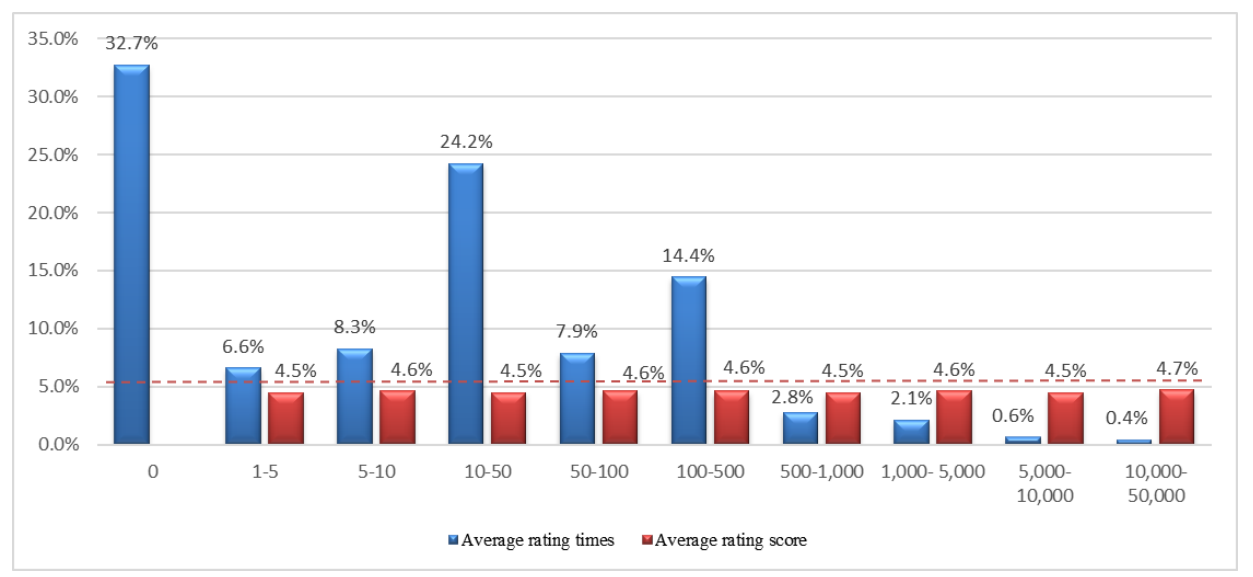


Figure 7 Evaluated apps and their privacy evaluation scores

\section{Update apps on Google Store}

The process of updating apps is an important process especially in keeping personal information private or possibly retrieving them, which claimed essential aiming to be improving the quality of applications. It was found that the updates are strange, normally adding new services, addressing previous problems and errors, improving the general appearance of the application, updating privacy information and its presentation, and others. Figure 8 shows the general rate of the latest updates on the collected application systems, it was found that $51.6 \%$ of the total apps had updated operations during the year $1440 \mathrm{AH}$, while $19.8 \%$ were updated during the last three months (Shawwal, Dhu alQi'dah, Dhu al-Hijjah for the year $1440 \mathrm{AH})$. The results also showed the existence of a group of apps that did not undergo any update during the years $1431 \mathrm{AH}-1435 \mathrm{AH}$, which constituted $6.4 \%$ of the total number of apps, assumed to be higher in preserving privacy consideration.

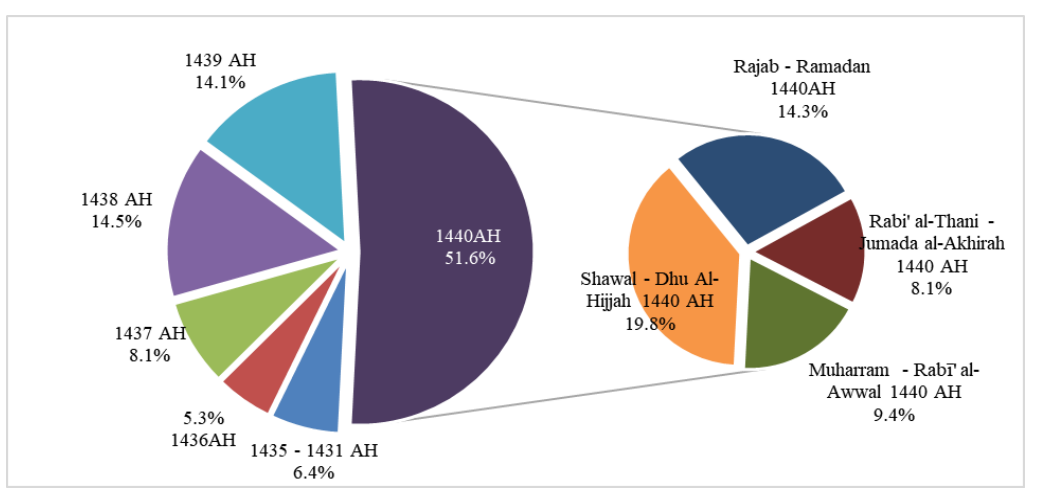

Figure 8 Updating Apps on Google Play during (1431 AH- 1440AH)

\section{Classification of Apps by size}

The best privacy considered app in its utilization is the app that balances between the efficiency of the functions contained in the app and the efficiency of mobile devices in terms of memory, processor, screen size, etc, without degrading security level. Figure 9 clearly shows that the largest size of apps increases steadily with time. This is considered functionally reasonable due to the continuous development in smart device technologies, but revealed the private information of the user's devices capability especially if not able handle larger sizes forcing them to change apps. This indication gave 
idea of the luxury level of the guests, where the largest application size reached $100 \mathrm{MB}$ in the year $1440 \mathrm{AH}$, followed by $94 \mathrm{MB}$ in the year $1439 \mathrm{AH}$ compared to reaching $34 \mathrm{MB}$ sized apps for years between $1431 \mathrm{AH}-1435 \mathrm{AH}$.

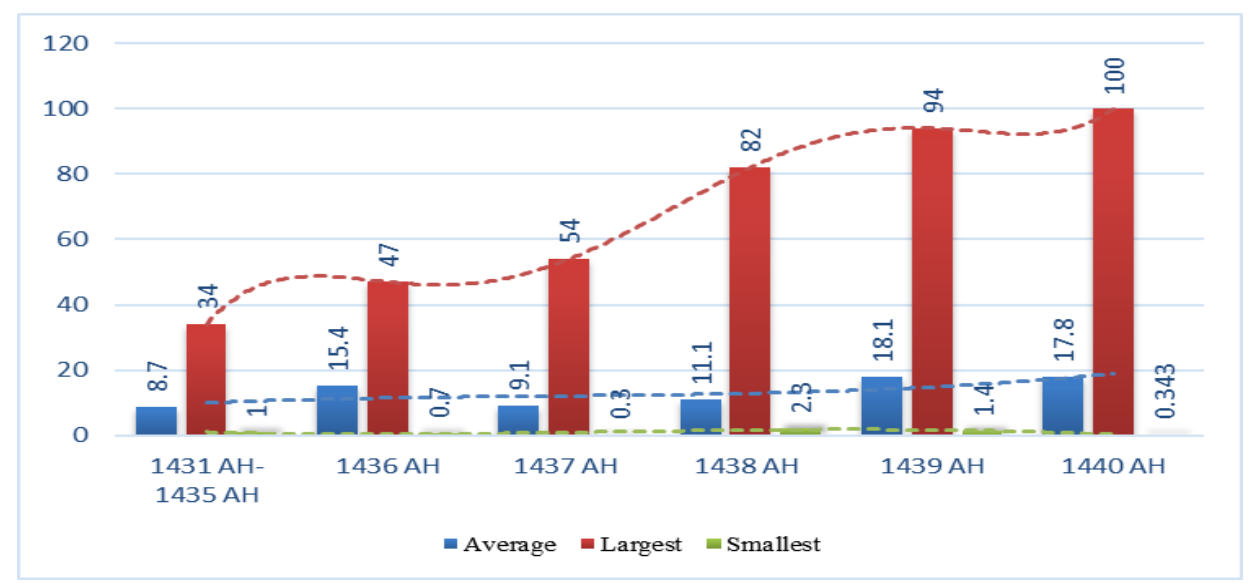

Figure 9 Classification of Apps by size

\section{EVALUATION OF GOVERNMENTAL APPS}

The research further investigated the apps that have been developed and fully controlled by the government of Saudi Arabia. These apps have been exposed to private information much more than others. Their functionality run interestingly well and applied highest level of security measures. The research highlighted each apps pros and cons aiming to provide useful evaluation metric for solving more personal challenges to come.

\section{Apps Selection and Evaluation Tool}

Nine apps are found officially linked to government sectors of Kingdom of Saudi Arabia. They have been built professionally to provide different services to Hajj and Umrah rituals, which are elected for in-depth personal evaluating using a popular mobile app rating scale called MARS method. It is to be mentioned that this MARS evaluation is intended for user dominant development and improvement and not specified for security investigation. Therefore, in this research we utilized this MARS tool for raising the personal challenges hoping to provide constructive regulations. The elected governmental apps considered in this research accompanied with their specifications are given in Table 3.

Table 3 Elected governmental apps and their personal specifications

\begin{tabular}{|c|c|c|c|c|c|c|c|c|c|}
\hline & $\begin{array}{c}\text { Application } \\
\text { Name }\end{array}$ & Publisher & Provider & $\begin{array}{c}\text { Reviews } \\
\text { rate/\# of }\end{array}$ & $\begin{array}{c}\text { Last } \\
\text { Update }\end{array}$ & $\begin{array}{c}\text { Download } \\
\text { times }\end{array}$ & $\begin{array}{c}\text { Size } \\
(\mathrm{MB})\end{array}$ & $\begin{array}{c}\text { Languages } \\
\text { Number of } \\
\text { Services }\end{array}$ \\
\hline
\end{tabular}


Journal of Engg. Research Online First Article

\begin{tabular}{|c|c|c|c|c|c|c|c|c|c|}
\hline & & & & $\begin{array}{c}\text { Reviewe } \\
\text { rs }\end{array}$ & & & & & \\
\hline 1 & Manasikana & $\begin{array}{l}\text { Ministry Of } \\
\text { Haj \& Umrah }\end{array}$ & $\begin{array}{l}\text { Ministry of Haj } \\
\text { \& Umrah }\end{array}$ & $4.6 / 457$ & $\begin{array}{c}\text { 10-Sep- } \\
18\end{array}$ & $\begin{array}{c}10,000- \\
50,000\end{array}$ & 94 & 9 languages & 17 \\
\hline 2 & Alharamain & $\begin{array}{l}\text { General } \\
\text { Presidency of } \\
\text { Haramain } \\
\end{array}$ & \begin{tabular}{|l|} 
General \\
Presidency of \\
Haramain
\end{tabular} & $4 / 585$ & $\begin{array}{c}\text { 24-Sep- } \\
19\end{array}$ & $\begin{array}{l}50,000- \\
100,000\end{array}$ & 38 & 3 languages & 14 \\
\hline 3 & $\begin{array}{l}\text { Hajj and } \\
\text { Umrah } \\
\text { Navigator }\end{array}$ & Saudi Post & Saudi Post & $4.1 / 152$ & 30-Jul-19 & $\begin{array}{c}10,000- \\
50,000\end{array}$ & 16 & $\begin{array}{c}17 \\
\text { languages }\end{array}$ & 4 \\
\hline 4 & AlMaqsad & \begin{tabular}{|l} 
General \\
Presidency of \\
Haramain
\end{tabular} & $\begin{array}{l}\text { General } \\
\text { Presidency of } \\
\text { Haramain }\end{array}$ & $4.8 / 387$ & $\begin{array}{c}\text { 31-Jan- } \\
19\end{array}$ & $\begin{array}{l}50,000- \\
100,000\end{array}$ & 34 & 2 languages & 2 \\
\hline 5 & $\begin{array}{l}\text { Umra e- } \\
\text { services }\end{array}$ & $\begin{array}{l}\text { Ministry Of } \\
\text { Haj \& Umrah }\end{array}$ & $\begin{array}{l}\text { Ministry of Haj } \\
\text { \& Umrah }\end{array}$ & $4.4 / 476$ & 4-Jul-19 & $\begin{array}{l}50,000- \\
100,000\end{array}$ & 22 & 6 languages & 2 \\
\hline 6 & Ershad & $\begin{array}{l}\text { Ministry Of } \\
\text { Haj \& Umrah }\end{array}$ & $\begin{array}{l}\text { Ministry of Haj } \\
\text { \& Umrah }\end{array}$ & 4/101 & 1-Aug-19 & $\begin{array}{c}10,000- \\
50,000 \\
\end{array}$ & 15 & 2 languages & 2 \\
\hline 7 & $\begin{array}{l}\text { Internal } \\
\text { Umrah }\end{array}$ & $\begin{array}{l}\text { Ministry Of } \\
\text { Haj \& Umrah }\end{array}$ & $\begin{array}{l}\text { Ministry of Haj } \\
\text { \& Umrah }\end{array}$ & - & \begin{tabular}{|c|} 
19-Mar- \\
19 \\
\end{tabular} & $\begin{array}{c}1,000- \\
5,000\end{array}$ & 36 & 2 languages & 1 \\
\hline 8 & Tarwiah & $\begin{array}{l}\text { National Water } \\
\text { Company }\end{array}$ & $\begin{array}{l}\text { National Water } \\
\text { Company }\end{array}$ & $4.7 / 167$ & 25-Jul-19 & $\begin{array}{c}10,000- \\
50,000\end{array}$ & 8.3 & 7 languages & 3 \\
\hline 9 & $\begin{array}{l}\text { Saudia } \\
\text { Umrah }\end{array}$ & $\begin{array}{l}\text { Saudi Arabian } \\
\text { Airlines }\end{array}$ & $\begin{array}{l}\text { Saudi Arabian } \\
\text { Airlines }\end{array}$ & $2.5 / 10$ & $\begin{array}{c}\text { 27-Dec- } \\
18\end{array}$ & $\begin{array}{l}1,000- \\
5,000\end{array}$ & 5.5 & 2 languages & 4 \\
\hline
\end{tabular}

The category of MARS personal evaluation tool is given in Table 4 which contains five classifications for evaluating the quality of apps: engagement, functionality, aesthetics, information, and subjective quality. A total of 99 different personal evaluation results was obtained for the selected governmental apps, where eleven specialists in information technology participated in the evaluation private process. The participants have been chosen randomly holding different academic degrees and practical experiences, from the Custodian of the Two Holy Mosques Institute for Hajj and Umrah Research.

Table 4 Category of MARS personal evaluation tool

\begin{tabular}{|c|l|l|l|l|}
\hline Category & \multicolumn{4}{|c|}{ Items } \\
\hline \multirow{2}{*}{ Engagement } & Entertainment & Interest & Customization & Interactivity \\
\cline { 2 - 5 } & Target group & & & \\
\hline Functionality & Performance & Ease of use & Navigation & $\begin{array}{c}\text { Gestural } \\
\text { design }\end{array}$ \\
\hline Anformetics & Layout & Graphics & Visual appeal & \\
\hline \multirow{2}{*}{ Subjective quality } & $\begin{array}{l}\text { Accuracy of } \\
\text { app description }\end{array}$ & Goals & $\begin{array}{c}\text { Quality of } \\
\text { information }\end{array}$ & $\begin{array}{l}\text { Quantity of } \\
\text { information }\end{array}$ \\
\cline { 2 - 5 } & $\begin{array}{l}\text { Visual } \\
\text { information }\end{array}$ & Credibility & Evidence base & \\
\cline { 2 - 5 } & Would you recommend this app? \\
\cline { 2 - 5 } & Amount of time that you spend on an app? \\
\cline { 2 - 5 } & Would you pay for this app? \\
\cline { 2 - 5 } & What is your overall star rating of the app? \\
\hline
\end{tabular}

The investigation asked each person to privately review the nine selected governmental apps before starting the real evaluation process. Then the work has been commenced in interesting manner revealing attractive personal privacy remarks as elaborated next. 


\section{Analysis and Discussion}

MARS tool was used to personally evaluate the Saudi government developed apps for Hajj and Umrah. The privacy evaluation studied every app proper confidentiality and disclosure measures. The measure figure-of-merit is graded from 1 to 5, where "1" indicates a very poor evaluation score and "5" indicates a very good evaluation. This evaluation measure considered the app's privacy practices before and after the app is downloaded revealing the correct remarks to be trusted. For example, the measure examined each Hajj and Umrah app's published info looking into how users can learn about some of the data types the app may collect, and whether that data is linked to them or used to track them. The privacy evaluation provided estimation about most commonly used app's privacy observations, counting the possible auto-recording of data personal practices as well as the third-party associates whose codes are found integrated running within the apps. The results of this apps evaluation are given in Figure 10, whereas Table 5 provides the detailed results of evaluated apps.

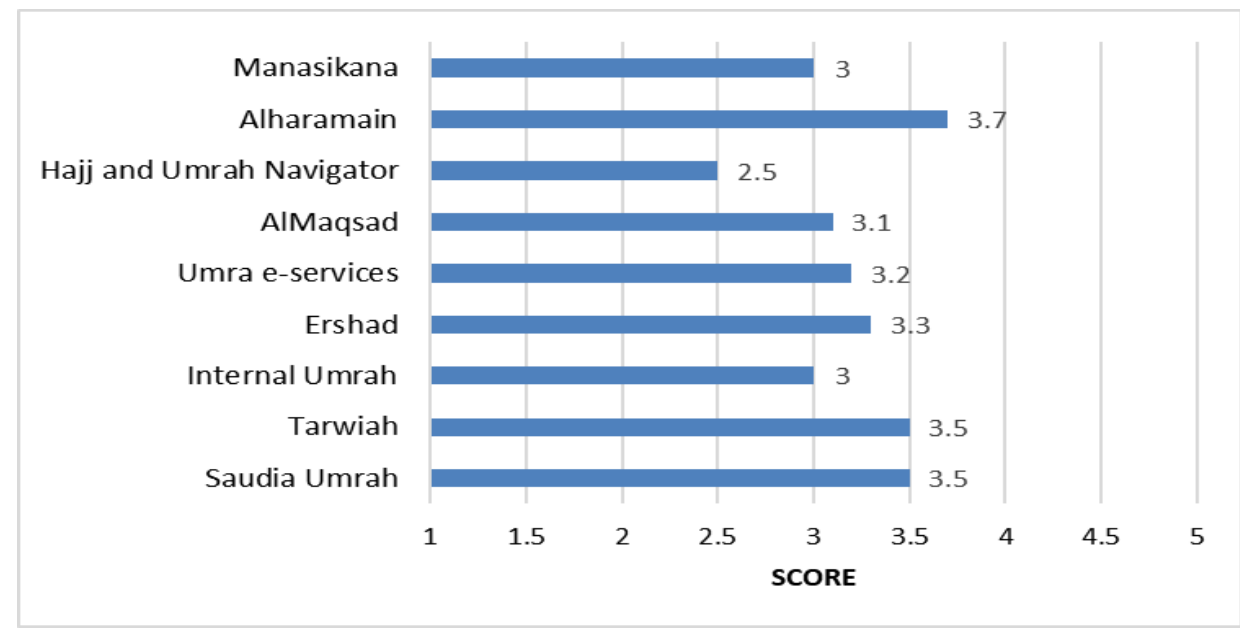

Figure 10 Results of apps privacy evaluation

\begin{tabular}{|l|c|c|c|c|c|c|}
\hline \multicolumn{1}{|c|}{ Apps } & Engagement & Functionality & Aesthetics & Information & $\begin{array}{c}\text { Subjective } \\
\text { quality }\end{array}$ & Total \\
\hline Manasikana & 2.8 & 3.4 & 3.2 & 3.4 & 2.4 & $\mathbf{3}$ \\
\hline Alharamain & $\mathbf{3 . 9}$ & 3.7 & 3.9 & $\mathbf{3 . 8}$ & $\mathbf{3 . 2}$ & $\mathbf{3 . 7}$ \\
\hline Hajj and Umrah Nav. & 2.4 & 2.5 & 2.6 & 3.2 & 1.9 & $\mathbf{2 . 5}$ \\
\hline AlMaqsad & 3.2 & 3.5 & 3.2 & 3.4 & 2.4 & $\mathbf{3 . 1}$ \\
\hline Umra e-services & 2.7 & 3.9 & 3.3 & 3.6 & 2.7 & $\mathbf{3 . 2}$ \\
\hline Ershad & 3 & 4 & 3.4 & 3.4 & 2.7 & $\mathbf{3 . 3}$ \\
\hline Internal Umrah & 2.7 & 3.7 & 3.4 & 3.3 & 2 & $\mathbf{3}$ \\
\hline Tarwiah & 3.5 & $\mathbf{4 . 3}$ & 3.6 & 3.5 & 2.5 & $\mathbf{3 . 5}$ \\
\hline
\end{tabular}




\begin{tabular}{|l|l|l|l|l|l|l|}
\hline Saudia Umrah & 3.3 & 3.6 & $\mathbf{4}$ & 3.5 & 2.9 & $\mathbf{3 . 5}$ \\
\hline
\end{tabular}

Table 5 Detailed results of evaluated apps

The results show that the highest MARS rating was found in Alharamain app, which received a score of "below good" with a score of 3.7 out of 5, followed by Tarwiah and Saudi Umrah apps with a rating of "above acceptable" of 3.5 for both. The results also indicated that the "functionality" criterion was the best criterion for all apps, with a rate of 3.6, which relates to the performance of the application, its private ease of use, and the movement between app interfaces. On the other hand, results showed that the lowest rating score, at a rate of 2.5, was obtained in "Subjective quality" criterion, which is related to the users' opinion on recommending others to use. Privacy features of time spent, payment for use, and overall app star rating reflected the weak acceptance of users in their adoption of the app in general.

The statistical private results also revealed that the two apps, Manasikana and Alharamain, were the most inclusive of services with 17 and 14 personal services, respectively, as shown in Table 5. On the other hand, the Hajj and Umrah Navigator app was unique in providing 17 languages, followed by the application of Manasikana in 9 languages. The research also noted that Manasikana app was the oldest in terms of updating apps on the Google Store, as the last update time was in more than 12 months, i.e. $12 / 29 / 1439 \mathrm{AH}$, respectively.

Generally, it was evident from the evaluation results that the Hajj and Umrah apps need more privacy accommodating attention by officials, specifically in their developing and updating software departments. The research suggests allocating a professional specific work security team that conducts the evaluation privacy process and provides appropriate suggestions to improve the security performance and efficiency of the apps.

\section{CONCLUSION}

In this paper, the available Hajj and Umrah apps on the Google Store were observed during the Hajj season $1440 \mathrm{AH}$ (2019) focusing on personal privacy features. The research studied 471 different apps 
including special governmental owned and controlled professional apps. The technical exploration for targeted apps started by searching four keywords in the name or description of the apps including: "حج", "عمرة" , “Hajj”, and “Umrah”, reveling interesting focused remarks. All available personal features were studied for general development as well as privacy consideration. The work wellthought-out personal users rating, number of users downloading and who have rated, the latest updates, the size of the apps, app languages, times of downloads, and services provided. The research personal feedback showed that the largest percentage of the studied apps mainly hint to Hajj and Umrah rituals services without checking privacy authenticity indicating possible untrusted actions. The results general overview showed that the most desired services among users was to watch live channels of the Two Holy Mosques which is not mostly intended service within the apps.

The paper also evaluated personal privacy via professional group study of Hajj and Umrah apps by participating of specialists in the field of information technology from the Custodian of the Two Holy Mosques Institute for Hajj and Umrah Research. Personal privacy remarks showed that the app serving watching the Two Holy Mosques had the best average MARS score compared to other applications with a score of 3.7 out of 5, followed by Tarawiyah and Saudi Umrah apps, with a score of "above acceptable" of 3.5 for both. In addition, it was noticed that there were sub-acceptable evaluation scores related to the general satisfaction of users in their use of the studied applications, as the average score for Subjective Quality of the applications studied was 2.5 out of 5, which reflects the need for more development work and effort to improve the services provided as well as personal security measures involvement as essential research prospective.

The research progress remarked many general explorations that have dealt with similar mobile apps issues in general, but cannot be used practically and efficiently for Hajj and Umrah services considering IoT and smart crowd management needs via available wireless and mobile technologies as well as the framework remarks of secure app computing (Kheshaifaty \& Gutub, 2020) and current arithmetic communication hardware and effective speeds analysis (Gutub, 2007). In other words, this research highlighted clearly that Hajj and Umrah apps studies is needed to be further considered for 
upcoming research, i.e. explored from current integrated IoT apps privacy smartness (Alassaf \& Gutub, 2019) in terms of transmission and architecture complexity (Gutub et al., 2011), sensing ebanking and cost (Al-Shaarani et al., 2020), as well as energy consumption (Gutub et al., 2010), data classification (Savas et al., 2005), security (Gutub \& Al-Qurashi, 2020), reliability (Parvez \& Gutub, 2011), scalability (Abdelgawad et al., 2014), and computing efficiency (Gutub, 2007a). The apps improvement work and its current focus is still in its early stage for experience convenience, but can be used as background building foundation for future related Hajj and Umrah research to come. 


\section{REFERENCES}

Abdelgawad, H., Shalaby, A., Abdulhai, B., \& Gutub, A. 2014. Microscopic modeling of large-scale pedestrian-vehicle conflicts in the city of Madinah, Saudi Arabia. Journal of Advanced Transportation 48(6): 507-525.

Alassaf, N. \& Gutub, A. 2019. Simulating Light-Weight-Cryptography Implementation for IoT

Healthcare Data Security Applications. International Journal of E-Health and Medical Communications (IJEHMC) 10(4): 1-15.

Alharthi, N. \& Gutub, A. 2017. Data Visualization to Explore Improving Decision-Making within Hajj Services. Scientific Modelling and Research, 2(1): 9-18.

Almutairi, S., Gutub, A., \& Al-Ghamdi, M. 2019. Image Steganography to Facilitate Online Students Account System. Review of Business and Technology Research (RBTR) 16(2): 43-49.

Almutairi, S., Gutub, A., \& Al-Juaid, N. 2020. Motivating Teachers to Use Information Technology in Educational Process within Saudi Arabia. Technology Enhanced Learning 12(2): 200-217.

Alsaidi, A., Gutub, A., \& Alkhodaidi, T. 2019. Cybercrime on Transportation Airline. Journal of Forensic Research 10(4): 449.

Al-Shaarani, F., Basakran, N., \& Gutub, A. 2020. Sensing e-Banking Cybercrimes Vulnerabilities via Smart Information Sciences Strategies. RAS Engineering and Technology 1(1): 1-9.

Aly, S., Alghamdi, T., Salim, M., \& Gutub, A. 2013. Data Dissemination and Collection Algorithms for Collaborative Sensor Devices Using Dynamic Cluster Heads. Trends in Applied Sciences Research 8(2): 55-72.

Aly, S., AlGhamdi, T., Salim, M., Amin, H., \& Gutub, A. 2014. Information Gathering Schemes for Collaborative Sensor Devices. Procedia Computer Science 32: 1141-1146.

Aly, S. \& Gutub, A. 2018. Intelligent Recognition System for Identifying Items and Pilgrims. NED University Journal of Research 15(2): 17-23.

Baskoro, K. \& Widyanti, A. 2018. Usability Evaluation on an Indonesian Mobile Application for Small Business Lending. IEEE International Conference on Information Technology Systems and 
Innovation (ICITSI), pp. 148-153.

Bin-Hureib, E. \& Gutub, A. 2020. Enhancing Medical Data Security via Combining Elliptic Curve Cryptography with 1-LSB and 2-LSB Image Steganography. International Journal of Computer Science and Network Security (IJCSNS) 20(12): 232-241.

Chavez, S., Fedele, D., Guo, Y., Bernier, A., Smith, M., Warnick, J., \& Modave, F. 2017. Mobile apps for the management of diabetes. Diabetes Care 40(10): 145-146.

Curtis, S., Zafar, B., Gutub, A., \& Manocha, D. 2013. Right of Way: Asymmetric Agent Interactions in Crowds. The Visual Computer 29(12): 1277-1292.

Farooqi, N., Gutub, A., \& Khozium, M.O. 2019. Smart Community Challenges: Enabling IoT/M2M Technology Case Study. Life Science Journal 16(7): 11-17.

Fraynt, R., Cooper, D., Edwards-Stewart, A., Hoyt, T., Micheel, L., Pruitt, L., Skopp, N., \& Smolenski, D. 2018. An evaluation of mobile applications designed to assist service members and veterans transitioning to civilian life. Psychological services, 15(2): 208-215.

Gafni R. 2009. Usability issues in mobile-wireless information systems. Issues in Informing Science and Information Technology 6(1): 755-769.

Gutub, A. 2007. High Speed Hardware Architecture to Compute GF(p) Montgomery Inversion with Scalability Features. IET (IEE) Proceedings Computers and Digital Techniques 1(4): 389-396.

Gutub, A. 2007a. Efficient Utilization of Scalable Multipliers in Parallel to Compute GF(p) Elliptic Curve Cryptographic Operations. Kuwait Journal of Science \& Engineering (KJSE) 34(2): 165-182.

Gutub, A. \& Aly, S. 2018. Trialing a Smart Face-recognition Computer System to Recognize Lost People Visiting the Two Holy Mosques. Arab Journal of Forensic Sciences \& Forensic Medicine (AJFSFM) 1(8): 1120-1133.

Gutub, A., Al-Juaid, N., \& Khan, E. 2019. Counting-Based Secret Sharing Technique for Multimedia Applications. Multimedia Tools and Applications (MTAP) 78: 5591-5619.

Gutub, A. \& Al-Qurashi, A. 2020. Secure Shares Generation via M-Blocks Partitioning for CountingBased Secret Sharing. Journal of Engineering Research 8(3): 91-117. 
Gutub, A., El-Shafe, A., \& Aabed, M. 2011. Implementation of a pipelined modular multiplier architecture for GF(p) elliptic curve cryptography computation. Kuwait Journal of Science and Engineering (KJSE) 38(2B): 125-153.

Gutub, A. \& Fattani, M. 2007. A Novel Arabic Text Steganography Method Using Letter Points and Extensions. International Journal of Computer, Electrical, Automation, Control and Information Engineering 1(3): 502-505.

Gutub, A., Ghouti, L., Elarian, Y., Awaideh, S., \& Alvi, A. 2010. Utilizing Diacritic Marks for Arabic Text Steganography”, Kuwait Journal of Science \& Engineering (KJSE) 37(1): 89-109.

Hassan, F.S. \& Gutub, A. 2021. Improving data hiding within colour images using hue component of HSV colour space. CAAI Transactions on Intelligence Technology, IET (IEE), in press. https://doi.org/10.1049/cit2.12053

Kaysi, I., Alshalalfah, B., Shalaby, A., Sayegh, A., Sayour, M., \& Gutub, A. 2013. Users' Evaluation of Rail Systems in Mass Events: Case Study in Mecca, Saudi Arabia. Journal of the Transportation Research Board 2350(1): 111-118.

Kaysi, I., Alshalalfeh, B., Sayour, M., \& Gutub, A. 2012. Rapid transit service in the unique context of Holy Makkah: assessing the first year of operation during the 2010 pilgrimage season. WIT Transactions on The Built Environment 128: 253-267.

Khan, E. \& Shambour, M. 2018. An analytical study of mobile applications for Hajj and Umrah services. Applied computing and informatics, 14(1): 37-47.

Kheshaifaty, N. \& Gutub, A. 2020. Preventing Multiple Accessing Attacks via Efficient Integration of Captcha Crypto Hash Functions. International Journal of Computer Science and Network Security (IJCSNS) 20(9): 16-28.

Kim, S., Guy, S., Hillesland, K., Zafar, B., Gutub, A., \& Manocha, D. 2015. Velocity-Based Modeling of Physical Interactions in Dense Crowds. The Visual Computer 31: 541-555.

Nouri, R., Niakan-Kalhori, S., Ghazisaeedi, M., Marchand, G., \& Yasini, M. 2018. Criteria for assessing the quality of mHealth apps: a systematic review. Journal of the American Medical 
Informatics Association 25(8): 1089-1098.

Parvez, M. \& Gutub, A. 2011. Vibrant Color Image Steganography using Channel Differences and Secret Data Distribution. Kuwait Journal of Science and Engineering (KJSE) 38(1B): 127-142.

Savas, E., Naseer, M., Gutub, A., \& Koc, C.K. 2005. Efficient Unified Montgomery Inversion with Multi-bit Shifting. IEE Proceedings Computers and Digital Techniques 152(4): 489-498.

Samkari, H. \& Gutub, A. 2019. Protecting Medical Records against Cybercrimes within Hajj Period by 3-layer Security. Recent Trends in Information Technology and Its Application 2(3): 1-21.

Serra, L., Carvalho, L., Ferreira, L., Vaz, J., \& Freire, A. 2015. Accessibility evaluation of egovernment mobile applications in Brazil. Procedia Computer Science 67: 348-357.

Shambour, M. \& Gutub, A. 2021. Progress of IoT Research Technologies and Applications Serving Hajj and Umrah", Arabian Journal for Science and Engineering (AJSE), in press (2021) https://doi.org/10.1007/s13369-021-05838-7

Shambour, M. \& Khan, E. 2019. Heuristic Approach for Distributing Pilgrims over Mina Tents. Journal of King Abdulaziz University: Engineering Sciences (30)2: 11-23.

Stoyanov, S.R., Hides, L., Kavanagh, D.J., Zelenko, O., Tjondronegoro, D., \& Mani, M. 2015. Mobile App Rating Scale: A new tool for assessing the quality of health mobile apps. JMIR mHealth and uHealth 3(1): 1-9. 